\title{
Is Dopamine Agonist Therapy Associated with Developing Pathological Gambling in Parkinson's Disease Patients?
}

\author{
Ramin Zand \\ The International Institute of Health Studies, Ottawa, Ont., Canada
}

\author{
Key Words \\ Parkinson's disease - Dopamine agonists - Impulse control \\ disorders $\cdot$ Problem gambling
}

\begin{abstract}
In recent years, improving the quality of life and the level of functioning in Parkinson's disease patients has become the main challenge of all therapeutic protocols for this chronic disease. Hence, identifying comorbid psychiatric conditions is the ambition of many studies in the field. To date, a few research studies have investigated the development of problem gambling as a potential side effect of dopamine agonist medications. However, there are still controversies among experts in the field. Thus far, published reports have been able to neither demonstrate the extent of risk for gambling-related problems nor study the correlation of dosage with this potential adverse effect among Parkinson's disease patients treated with dopaminergic medications. In fact, prospective epidemiologic studies are needed to technically estimate the incidence rate and the relative risk of pathological gambling among patients with Parkinson's disease and to determine the correlation between dosage of these medications and the development of pathological gambling.

Copyright $\odot 2008$ S. Karger AG, Basel
\end{abstract}

\section{KARGER}

Fax +41613061234

E-Mail karger@karger.ch

www.karger.com
(C) 2008 S. Karger AG, Basel

$0014-3022 / 08 / 0594-0183 \$ 24.50 / 0$

Accessible online at:

www.karger.com/ene

\section{Introduction}

Our current knowledge introduces Parkinson's disease (PD) as a fusion of movement disorder, intellectual impairment, and psychiatric comorbidities. In recent years, improving the quality of life and the level of functioning in PD patients has become the main challenge of all therapeutic protocols for this chronic disease. Hence, identifying comorbid psychiatric conditions is the ambition of many studies in the field. To date, many research studies have investigated behavioral side effects as related to antiparkinsonian medications; obsessive-compulsive behaviors such as cleaning, rearranging, and ordering, and problem gambling (PG) have been reported as the potential side effects of dopamine agonist medications [1-11].

The term 'problem gambling' is commonly used in a variety of ways. In some literature, it refers to gamblingrelated difficulties that are less serious than pathological gambling; however, in other situations, the term indicates all gambling behavioral patterns and pathological gambling as the extreme end of the gambling spectrum $[12,13]$. Pathological gambling, classified in the DSM-IV as a compulsive disorder, is defined as failure to resist gambling impulses despite negative personal, family, 
Table 1. Case studies on association of dopamine agonist therapy and PG in PD

\begin{tabular}{|c|c|c|c|c|}
\hline Source & Type of study & $\begin{array}{l}\text { Sample } \\
\text { size }\end{array}$ & $\begin{array}{l}\text { Patients who } \\
\text { developed PG }\end{array}$ & $\begin{array}{l}\text { Medication } \\
\text { at onset of PG }\end{array}$ \\
\hline Dodd et al. [1] & case series & - & 11 & levodopa + DA \\
\hline Avanzi et al. [3] & case report & - & 2 & levodopa + DA + COMT \\
\hline Kurlan [4] & case report & - & 2 & levodopa + DA \\
\hline Driver-Dunckley et al. [2] & retrospective database review & 1,884 & 9 & levodopa + DA \\
\hline Montastruc et al. [5] & case report & - & 1 & levodopa + DA \\
\hline Gschwandtner et al. [7] & case report & - & 2 & levodopa + DA \\
\hline Seedat et al. [8] & case report & - & 1 & $\mathrm{DA}+$ selegiline \\
\hline Molina et al. [6] & retrospective database review & 250 & 12 & levodopa $+?^{1}$ \\
\hline
\end{tabular}

DA = Dopamine agonists; COMT = catechol-O-methyltransferase. DA included pergolide, ropinirole, pramipexole, pergolide, bromocriptine, and cabergoline.

${ }^{1}$ Only levodopa is mentioned as the main medication and other medications have not been indicated.

Table 2. Epidemiologic studies (cross-sectional and case-control studies) on association of dopamine agonist therapy and PG in PD

\begin{tabular}{lllll}
\hline Source & Type of study & Sample size & $\begin{array}{l}\text { Patients who } \\
\text { developed PG }\end{array}$ & $\begin{array}{l}\text { Medication } \\
\text { at onset of PG }\end{array}$ \\
\hline Voon et al. [9] & $\begin{array}{l}\text { retrospective } \\
\text { case-control }\end{array}$ & $\begin{array}{l}\text { case: } 21 \\
\text { control: } 42\end{array}$ & N/A & $\begin{array}{l}\text { adjunctive dopamine agonist therapy, } \\
\text { higher dose }\end{array}$ \\
\hline Weintraub et al. [10] & $\begin{array}{l}\text { cross-sectional } \\
\text { screening interview }\end{array}$ & 272 & 13 & not enough info \\
\hline Voon et al. [1] & $\begin{array}{l}\text { cross-sectional } \\
\text { screening study }\end{array}$ & 297 & 21 & $\begin{array}{l}\text { any subtypes, } \\
\text { any doses }\end{array}$ \\
\hline
\end{tabular}

and vocational consequences $[14,15]$. The essential features of pathological gambling are presently defined as (1) the continuous or periodic loss of control over gambling; (2) a progression in gambling frequency and amounts wagered, in the preoccupation with gambling and in obtaining monies with which to gamble, and (3) a continuation of gambling involvement despite adverse consequences [14]. The incidence of pathological gambling in the general population ranges from 0.3 to $1.6 \%$ $[2,9]$. Increasing gambling participation is associated with concerns about adverse mental health, social health and financial outcomes which involves individuals, families, and communities. Recent studies have indicated that dopamine function is associated with pathological gambling through reward and reinforcement mechanisms $[15,16]$.

\section{Studies Review}

In recent years, several case reports and retrospective studies have suggested a correlation between dopamine agonist therapy in PD and gambling-related problems [110]; however, there has been no previous prospective epidemiologic study investigating this correlation. In addition, the clinical trials performed on dopamine agonist agents did not document any correlation between these drugs and pathological gambling. Tables 1 and 2 summarize the published studies and database reviews which have investigated the association between developing PG and dopamine agonist therapy in PD patients.

Having reviewed the results of previous case series and case report studies (table 1) [1-8], it is evident that all patients except one were on both levodopa and dopamine agonist therapy - the case report study conducted by Molina et al. [6] has been excluded since there was not 
enough information about other prescribed medication in this study. It is also noticeable that the commonly prescribed dopamine agonist agents have been associated with problem gambling. Dopamine agonist medications were pramipexole (19 of 28 cases), ropinirole ( 4 of 28 cases), pergolide (3 of 28 cases), cabergoline (1 of 28 cases) and bromocriptine (1 of 28 cases).

Dodd et al. [1] reported 11 cases where patients developed pathological gambling after starting therapy with a dopamine agonist - pramipexole in 9 cases and ropinirole in another 2 cases. In this study, all patients who developed pathological gambling were on high doses of medications; 7 patients developed pathological gambling within 1-3 months of achieving the maintenance dose or with dose escalation. The results also indicated that the pathological gambling resolved in 8 out of 11 patients when the dopamine agonist was tapered or discontinued. This report, however, did not include the total number of patients exposed to pramipexole, ropinirole or other dopamine agonist agents, so the incidence of pathological gambling could not be estimated. There is also not enough information available about the retrospective database review conducted by Driver-Dunckley et al. [2]. They reported 9 cases of pathological gambling during a retrospective database review of 1,884 patients with PD in a 12 -month period. The results of this study indicated an overall incidence rate of $0.5 \%$ for pathologic gambling among $\mathrm{PD}$ patients regardless of medication type; the incidence of this behavior was $1.5 \%$ in the pramipexole group and $0.3 \%$ in the pergolide group. Moreover, DriverDunckley et al. reported that in 7 cases, the initiation of gambling occurred within 1 month of increasing the dosage of the prescribed dopamine agonist. The results also indicated that pathological gambling behavior declined in all cases following a decrease in dosage or switching to a dopamine agonist other than pramipexole.

Two cross-sectional studies $[10,11]$ along with a casecontrol study [9], published in 2006-2007, are three significant studies that investigated the association of dopamine agonist therapy and development of PG/impulse control disorders (ICDs) (table 2). Voon et al. [11] designed a cross-sectional study to prospectively screen 297 patients with PD. They found a prevalence rate of $7.2 \%$ for PG among patients receiving dopamine agonist medications compared to $3.4 \%$ among all PD patients regardless of medication subtype. This study was then followed by a case-control study to determine factors associated with dopaminergic medications in PD and developing PG [9]. In general, the results of these two studies indicated that PG was associated with dopamine agonist therapy and the onset of PD at a younger age $[9,11]$. The results of the latter study also indicated that PG was significantly associated with adjunctive dopamine agonist therapy but not with dopamine agonist monotherapy [9]. However, the duration of treatment has not been mentioned in the report. The research team also concluded that higher dopamine agonist dose, higher novelty-seeking score, and immediate family history of alcohol use disorders were associated with PG [9]. In a different cross-sectional study, Weintraub et al. [10] screened 272 PD patients to study the association of dopamine agonist therapy with (ICDs in PD. The results of this study indicated that younger age and higher dopamine agonist doses were associated with ICDs [10]. This study suffers from lack of data for the duration of treatment with dopamine agonist medications.

\section{Conclusion}

Having reviewed the first group of studies (table 1), it can be concluded that pramipexole, prescribed in two thirds of the cases, is a unique drug that is highly selective for the dopamine $\mathrm{D}_{3}$ receptor. Ropinirole and pergolide are relatively selective for the $\mathrm{D}_{3}$ receptor, although their specific affinity for the $\mathrm{D}_{3}$ receptor is less compared to pramipexole $[17,18]$. These pharmacologic factors may suggest a correlation between $\mathrm{D}_{3}$ receptors and gambling behaviors. The second group of studies (table 2), however, did not specify any association between medication subtypes and PG. It also has to be mentioned that none of the above studies have been designed to investigate the association of medication subtypes and PG. Further specifically designed epidemiologic studies are required to study the association of dopamine agonist subtypes with higher risk of developing PG.

There are still controversies among experts in the field. Thus far, published reports have been able to neither demonstrate the extent of risk for gambling-related problems nor study the correlation of dosage with this potential adverse effect among PD patients treated with dopaminergic medications. In fact, prospective epidemiologic studies are needed to technically estimate the incidence rate and the relative risk of pathological gambling among patients with PD and to determine the correlation between dosage of these medications and the development of pathological gambling. A prospective case-control or cohort study could be the next step to investigate these associations. 


\section{References}

-1 Dodd ML, Klos KJ, Bower JH, Geda YE, Josephs KA, Ahlskog JE: Pathological gambling caused by drugs used to treat Parkinson disease. Arch Neurol 2005;62:13771381.

-2 Driver-Dunckley E, Samanta J, Stacy M Pathological gambling associated with dopamine agonist therapy in Parkinson's disease. Neurology 2003;61:422-423.

3 Avanzi M, Uber E, Bonfa F: Pathological gambling in two patients on dopamine replacement therapy for Parkinson's disease. Neurol Sci 2004;25:98-101.

4 Kurlan R: Disabling repetitive behaviour in Parkinson's disease. Mov Disord 2004;19: 433-437.

5 Montastruc JL, Schmitt L, Bagheri H: Pathological gambling behavior in a patient with Parkinson's disease treated with levodopa and bromocriptine (in French). Rev Neurol Paris 2003;159:441-443.

6 Molina JA, Sainz-Artiga MJ, Fraile A, Jimenez-Jimenez FJ, Villanueva C, Orti-Pareja M, Bermejo F: Pathologic gambling in Parkinson's disease: a behavioral manifestation of pharmacologic treatment? Mov Disord 2000;15:869-872.
7 Gschwandtner U, Aston J, Renaud S, Fuhr $\mathrm{P}$ : Pathologic gambling in patients with Parkinson's disease. Clin Neuropharmacol 2001;24:170-172.

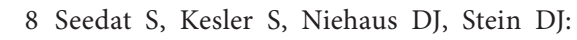
Pathological gambling behaviour: emergence secondary to treatment of Parkinson's disease with dopaminergic agents. Depress Anxiety 2000;11:185-186.

9 Voon V, Thomsen T, Miyasaki JM, de Souza M, Shafro A, Fox SH, Duff-Canning S, Lang AE, Zurowski M: Factors associated with dopaminergic drug-related pathological gambling in Parkinson disease. Arch Neurol 2007;64:212-216.

10 Weintraub D, Siderowf AD, Potenza MN, Goveas J, Morales KH, Duda JE, Moberg PJ, Stern MB: Association of dopamine agonist use with impulse control disorders in Parkinson disease. Arch Neurol 2006;63:969973.

11 Voon V, Hassan K, Zurowski M, Duff-Canning S, de Souza M, Fox S, Lang AE, Miyasaki J: Prospective prevalence of pathological gambling in Parkinson's disease. Neurology 2006;66:1750-1752.

12 Cox S, Lesieur HR, Rosenthal RJ, Volberg RA: Problem and Pathological Gambling in America: The National Picture. Columbia, National Council on Problem Gambling, 1997.
13 Lesieur HR: Costs and treatment of pathological gambling. Ann Am Acad Pol Soc Sci 1998; 556:153-171.

14 American Psychiatric Association: Diagnostic and Statistical Manual of Mental Disorders, ed 4. Washington, American Psychiatric Association, 1994.

15 Petry NM: Pathological Gambling: Etiology, Comorbidity, and Treatment. Washington, American Psychological Association, 2005, pp 13-16.

16 Moreyra P, Ibanez A, Liebowitz MR, SaizRuiz J, Blanco C: Pathological gambling: addiction or obsession. Psychiatr Ann 2002;32: 161-166.

17 Piercey MF: Pharmacology of pramipexole, a dopamine $\mathrm{D}_{3}$-preferring agonist useful in treating Parkinson's disease. Clin Neuropharmacol 1998;21:141-151.

18 Gerlach M, Double K, Arzberger T, Leblhuber F, Tatschner T, Riederer P: Dopamine receptor agonists in current clinical use: comparative dopamine receptor binding profiles defined in the human striatum. J Neural Transm 2003;110:1119-1127. 